\title{
A VINGANÇA DA CRIADA: sobre ler e usar a nova sociologia do
}

processo civil // David M. Trubek ${ }^{1}$

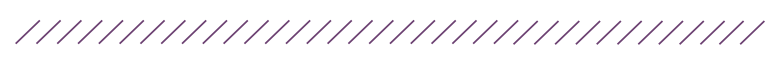

\section{Sumário}

\section{Introdução}

2 Processo transparente: uma descrição provisória das implicações da teoria clássica do direito para o processo civil

2.1 Pensamento Jurídico Clássico

2.2 Processo transparente

3 Realismo Jurídico e as origens das pesquisas empíricas no processo civil

3.1 A indeterminação dos sujeitos

3.2 Efeitos no pensamento sobre o processo

4 Mudanças Teóricas - Questionando o sujeito

5 Temas emergentes na sociologia crítica do processo

5.1 Negação do indivíduo autêntico

5.2 O direito e a Construção da Realidade Social

5.3 O direito e a Vitimização da Vítima

5.4 A Alternativa Comunitária e a Crítica da Adjudicação

5.5 A crítica da ADR e os discursos de necessidade

5.6 A discursividade do conhecimento social

6 Conclusão

7 Referências
1Professor de Direito Voss-Bascom e Diretor do Institute for Legal Studies da Universidade de Wisconsin-Madison. O autor cordialmente agradece o auxílio de Lisa Bower, da Universidade de Wisconsin-Madison, Departamento de Political Science e do Institute for Legal Studies, na pesquisa e análise deste artigo. O texto foi publicado originalmente em Law and Contemporary Problems 51(4), em outubro de 1988. Disponível em http://law.wisc.edu/facstaff/ trubek/pub_handmaiden_1989.pdf. Tradução: Michel Roberto Oliveira de Souza (doutorando na Faculdade de Direito da USP, com bolsa CAPES/CNPq). Revisão da tradução: Diogo R. Coutinho (Faculdade de Direito da USP). 


\section{Introdução}

Este simpósio oferece uma oportunidade de apresentar alguns desenvolvimentos importantes nos estudos empíricos de disputas civis, litigância e processo civil. Nos anos recentes, alguns estudiosos trabalhando na tradição da Law and Society (Direito e Sociedade) têm esboçado uma nova abordagem para o estudo desses fenômenos e têm articulado novos temas que desafiam entendimentos convencionais sobre o papel social do direito. Este artigo procura aclarar tal abordagem - que será chamada de "sociologia crítica do processo civil" - e esboçar alguns temas que emergem na recente literatura da Law and Society.

Há duas ideias fundamentais que fazem com que esses novos estudos sejam diferenciados. A primeira é uma visão distinta da relação entre direito e subjetividade. 0 pensamento jurídico há tempos tem se preocupado com essa relação e a questão de como interagem o direito e o sujeito humano existe há muito tempo. Entretanto, a maioria das discussões sobre essa questão tem tomado, de forma implícita ou explícita, a natureza do sujeito e a relação entre direito e subjetividade como não-problemáticas. Enquanto o pensamento jurídico e sociológico convencionais pressupõem que os sujeitos buscam o direito com objetivos pré-constituídos que o direito pretende fomentar, a sociologia crítica do processo civil explora maneiras pelas quais o direito simultaneamente cria o sujeito e ainda assim nega subjetividade autêntica.

A segunda ideia fundamental adotada na nova literatura é de que a pesquisa social é parte de um processo pelo qual a realidade social é construída. Compreensões anteriores haviam enxergado a natureza da pesquisa empírica em estudos jurídicos como reflexo de uma realidade pré-existente, desenhada para jogar luz sobre leis de interação humana objetivas e possivelmente invariantes. Rejeitando esta noção, a sociologia crítica do processo civil pressupõe que a pesquisa social é uma das maneiras pelas quais construímos a sociedade.

Uma abordagem verdadeiramente crítica dos estudos das disputas civis nasceu quando esses dois temas - a construção legal do sujeito e a construção da sociedade pelo conhecimento - foram unidos. Essa união afeta o modo pelo qual estudiosos definem seus papeis e concebem os seus objetos de estudo. Vários estudiosos da tradição do Law and Society que estudam disputas e litigância civil acabaram aceitando essa abordagem. Assim, é razoável falar sobre uma sociologia crítica do processo civil.

Para compreender uma perspectiva crítica no pensamento social, deve-se entender a tradição de filosofia do direito clássica contra a qual os críticos reagem. A premissa básica deste artigo é que a nova literatura da Law and Society é uma crítica da visão social do indivíduo, da sociedade e do direito que subjaz a muito do nosso pensamento sobre o processo civil hoje. Essa visão social é um conjunto de ideias sobre a natureza da personalidade, a função do direito, e a operação do processo, que foi articulada no século dezenove e que sobreviveu, com algumas alterações significativas introduzidas pelo realismo jurídico, até o presente. A Parte II deste artigo apresenta a visão original do século dezenove; a Parte III discute as modificações introduzidas pelo realismo. Seguindo essas discussões introdutórias nas quais a visão social subjacente a esse pensamento dominante é desenhada, o artigo volta-se para o trabalho crítico em si. A Parte IV introduz dois desenvolvimentos maiores na recente teoria social que levou alguns estudiosos da Law and Society a levantarem perguntas básicas concernentes à visão social dominante. A Parte $\mathrm{V}$ apresenta um panorama dos novos trabalhos ao identificar seis temas que podem ser vistos na literatura (1) negação pelo direito de um indivíduo autêntico; (2) a construção jurídica do indivíduo (self) e da sociedade; (3) a vitimização das vítimas por meio do direito; (4) a alternativa comunitária e a crítica da adjudicação; (5) a crítica aos métodos alternativos de resolução de conflitos (Alternative Dispute Resolution - "ADR") e os discursos de necessidade; e (6) a discursividade do conhecimento social.

\section{Processo transparente: uma descrição provisória das implicações da teoria clássica do direito para o processo civil}

Para identificar as visões sociais subjacentes ao pensamento que predomina sobre o processo, deve-se primeiro compreender a visão social do século dezenove, vários elementos dos quais ainda continuam a animar o pensamento atual. Para alcançar esse 
entendimento, deve-se olhar para trás no que deve ser chamado, seguindo o trabalho de vários historiadores do direito, de a era do "pensamento jurídico clássico"2, um modo de pensar sobre o direito, cuja influência compreende um período de 100 anos, de meados do século dezenove a meados do século vinte. ${ }^{3}$ A visão social subjacente ao pensamento jurídico clássico ainda influencia o pensamento atual sobre o processo e é importante entender os princípios que animaram o pensamento clássico e traçar suas implicações no campo do processo civil.

Infelizmente, nenhum relato desse tipo está atualmente disponível. Houve alguns estudos que tentaram identificar as ideias básicas sobre o direito e sociedade que dominaram no período clássico. ${ }^{4} \mathrm{Ne}-$ nhum, contudo, desenvolveu as implicações processuais dessas ideias. Assim, o relato necessário para começar essa história deve ser criado, não encontrado. Esta seção oferece um esboço provisório, derivando noções de processo das ideias mais básicas da natureza, função e aplicação do direito que prevaleceram no período clássico. Este esboço representará a ideia de "processo transparente".

\subsection{Pensamento Jurídico Clássico ${ }^{5}$}

O pensamento jurídico clássico estava baseado em três compromissos fundamentais: um entendimento individualista da personalidade, uma teoria liberal da sociedade e um entendimento formalista do direito. Para compreender por que esses compromissos levaram a uma noção de transparência do processo deve-se examinar cada um deles e ver como eles se interrelacionam.

2 Este termo foi retirado de Kennedy, 1980. Para maiores desenvolvimentos da ideia de pensamento jurídico clássico, ver Singer, 1982. Ver também Singer, 1988.

3 A identificação de períodos é um processo impreciso na história intelectual. Kennedy identificou o começo do pensamento jurídico clássico em 1850 e o seu fim em 1940. Kennedy, 1980, supra nota 1 , na página 3.

4 Ver supra nota 1 e fontes nela citadas. Ver também Peller, 1985. 50 relato do pensamento jurídico clássico nesta seção é uma síntese inspirada em várias fontes. Para as mais importantes dessas fontes, ver supra nota 1 e fontes nela citadas; Unger, 1975; Unger, 1976; Weber, 1980; Kennedy, 1976. Para uma interpretação da visão de Weber sobre o pensamento jurídico clássico, o qual Weber chamou de racionalidade legal formal, ver Trubek, 1986.
1. Personalidade. ${ }^{6}$ No pensamento clássico, a pessoa e portanto o sujeito jurídico, é um ator inteiramente constituído, autossuficiente e capaz de escolhas autônomas. Nem todos os seres humanos atendem a esse padrão de personalidade, então nem todos podem ser sujeitos jurídicos. Por exemplo, crianças, mulheres casadas e os doentes mentais não podem ser sujeito de direitos nesse sentido. De outro lado, aqueles que passam no teste da personalidade, tais como os homens brancos, presume-se serem capazes de agir de acordo com um conjunto de valores que eles escolheram livremente. No pensamento clássico, esses valores, e as escolhas a que esses valores levam, existem de forma inteiramente independente do direito.

2. Liberalismo. ${ }^{7}$ Em uma sociedade liberal, o propósito do direito é proteger a autonomia do indivíduo. Assim, o direito deve ser concebido para garantir que indivíduos sejam livres para exercer as escolhas que eles fazem, sujeito à liberdade análoga por parte de todos os outros. Para garantir essa liberdade, o direito confere poderes aos indivíduos e oferece imunidades contra privações causadas por terceiros. Assim, o liberalismo não é uma anarquia mas sim um sistema de liberdade ordenada. Ele requer um sistema de direito no qual algumas ações adotadas por indivíduos podem ser proibidas. 0 direito, entretanto, deve distinguir entre uma esfera na qual o indivíduo pode permanecer livre de todos os constrangimentos externos e uma esfera na qual tais constrangimentos não são apenas permitidos, mas necessários, porque sem essa distinção, a liberdade de uma pessoa se tornará a dominação de outra.

3. Formalismo. ${ }^{8}$ Para o direito proteger o indivíduo e proporcionar liberdade ordenada, ele deve ser formal em sua operação. Deve ser capaz de delimitar corretamente as esferas da liberdade e regu-

6 Ver Unger, 1975, supra nota 4, nas páginas 29-62; R. Unger, 1976, supra nota 4, nas páginas 23-37.

7 A visão clássica deste argumento pode ser encontrada em Locke, 1967. Para uma crítica da autonomia do sujeito do liberalismo, ver Sandel, 1962. Ver também Peller, 1985, supra nota 3, nas páginas 1193-207.

8 Para uma descrição do formalismo como um componente do pensamento jurídico clássico, ver Singer, 1988, supra nota 1, nas páginas 496-99. 
lação; definir o escopo dos poderes e imunidades de forma clara; bem como operar de forma previsível. Se as esferas são definidas incorretamente, o direito não trará a liberdade ótima desejada. Se os limites dos poderes e das imunidades não forem claros e se as respostas das instituições legais não forem previsíveis, os atores não serão capazes de exercer completamente a sua autonomia pelo medo de incorrer em sanções. Um sistema formal de justiça é simplesmente um nome para um sistema legal que pode traçar linhas corretas e aderir a elas. $O$ direito é considerado como um conjunto de declarações a partir do qual regras específicas que cobrem todas as interações sociais podem ser obtidas por meio de técnicas que todos aqueles que tenham o treinamento próprio podem utilizar para chegar ao mesmo resultado. Para os que aderem a esse formalismo, o conhecimento jurídico é tanto determinante quanto objetivo: há uma resposta certa e todo mundo deve aceitá-la.

\subsection{Processo transparente}

A teoria clássica do direito pressupunha que os sujeitos eram autônomos e pré-constituídos. Ademais, supôs que o direito estabelecia esferas claras e determinadas nas quais eles poderiam - ou não poderiam - exercer escolhas livres e sem constrangimento. As fronteiras dessas esferas eram delimitadas por direitos que derivaram das regras jurídicas. ${ }^{9}$ Esses direitos tinham que ser claros e cognoscíveis, porque de outra forma o indivíduo não teria conhecimento dos limites da esfera da autonomia que o sistema como um todo foi desenhado para proteger. ${ }^{10}$

Em tal sistema, o processo é um meio pelo qual a regra correta é aplicada aos fatos de uma disputa. Dadas as premissas do formalismo, deve haver uma regra correta para todos os conjuntos de fatos. E dadas as premissas do liberalismo, seria necessário - de tempos em tempos - aplicar essas regras para aqueles que se intrometem nas esferas protegidas.

Qualquer um que aceite esses princípios deve pensar o processo não simplesmente como um meio, mas

9 Ver Kennedy, 1976, supra nota 4; Singer, 1988, supra, nota 1, nas páginas 475-95.

10 Ver Kennedy, 1976, supra nota 4, nas páginas 1728-31. como um meio transparente - do tipo que não adiciona ou subtrai nada. As regras de um sistema formalista já estão lá. A regra correta não é feita, ao contrário, é descoberta por meio do processo. 0 processo não deve fazer uma diferença no resultado de uma disputa. Deve simplesmente garantir que o sistema gere a resposta certa, uma resposta que, por hipótese, já está presente em determinado sistema de direito formal. O pensamento clássico demanda um processo civil que minimize as chances de erro na seleção do princípio jurídico correto ou na determinação dos fatos corretos, mas pressupõe que tais princípios e fatos existem, para que então a transparência seja um objetivo realizável.

Outra característica da transparência é a ideia que de o processo não pode ter efeitos nos valores, objetivos e desejos daqueles que se utilizam do sistema. Por hipótese, os sujeitos jurídicos do pensamento clássico comparecem ao direito com seus objetivos já determinados; o direito deve dar suporte às suas pretensões ou rejeitá-las. 0 direito não deve tentar modificar seus objetivos ou suas razões para esses objetivos, porque fazê-lo violaria o princípio da personalidade autônoma e a ideia de que o direito serve somente para cumprir os objetivos escolhidos pelos indivíduos. 0 processo transparente toma os litigantes como eles vieram ao judiciário.

Estudiosos clássicos do direito não têm um conceito deliberado do processo transparente porque nunca ocorreu a eles que o processo deva ser algo que não transparente. Isso não significa que na era clássica ninguém se preocupou com o processo; é claro que as pessoas o fizeram. Mas a hipótese do autor - e sem maiores estudos históricos não pode ser mais do que uma hipótese - é que no pensamento clássico os objetivos do processo eram relativamente não problemáticos. O processo era para ser a criada da justiça, do modo como a justiça era definida no pensamento clássico. Essa definição implicava que o processo deveria ser um instrumento científico desenhado para identificar os princípios corretos e determinar os fatos verdadeiros. Deveria garantir que os sujeitos podem tanto invocar regras conhecidas em situações apropriadas, quanto estarem certos de que essas regras seriam aplicadas. Se o processo erguesse barreiras para a invocação de direitos preexistentes, ou 
distorcesse os resultados ditados pelas regras apropriadas, teria falhado no seu papel de criada.

Essa tentativa de deduzir uma teoria do processo das premissas do pensamento jurídico clássico pode fazer com que os estudiosos jurídicos clássicos soem ingênuos. Podem eles realmente terem pensado que as pessoas que procuram utilizar o direito não seriam afetados pelo seu contato com ele? Podem eles ter imaginado que o processo não tinha impacto no resultado substantivo dos casos? O autor duvida que eles eram tão ingênuos. Mas esse não é o ponto. A questão não é como eles avaliaram as reais instituições jurídicas em sua época, mas se consideraram a transparência um objetivo desejável e factível. $\mathrm{O}$ autor, apesar de não ter condições de provar isso, pensa que eles realmente o fizeram. Certamente, por um longo período na história, a elite jurídica acreditou na clássica ideia do direito ${ }^{11}$ e a noção de transparência é simplesmente uma dedução das premissas dessa ideia. Na medida em que os teóricos do pensamento jurídico clássico pensaram sobre o processo em geral, devem, portanto, ter imaginado que o que tem sido chamado de transparência era um objetivo viável mesmo que não fosse uma realidade presente.

\section{Realismo Jurídico e as origens das pesquisas empíricas no processo civil}

o Realismo Jurídico introduziu uma nova era no pensamento jurídico. Os Realistas alteraram alguns aspectos da narrativa clássica do direito, enquanto mantiveram outros. ${ }^{12}$ Eles rejeitaram o quadro clássico do conhecimento jurídico como objetivo e determinante, ao mesmo tempo que mantiveram a noção clássica de autonomia do sujeito. Essa mudança nas teorias sobre o direito teve um impacto direto no pensamento processual. A ideia de transparência processual, baseada nas premissas relativas à determinação do conhecimento jurídico, deixou de fazer sentido. No seu lugar veio o reconhecimento categórico que o processo e a substância estavam indissociavelmente imbricadas.

11 Ver Kennedy, 1980, supra nota 1, nas páginas 4-5; Singer, 1988 , supra nota 1 , nas páginas 478-82.

12 Ver Singer, 1988, supra nota 1, nas páginas 482-95.
Um dos resultados do pensamento Realista sobre o processo civil foi o desenvolvimento de pesquisas empíricas sobre litigância civil e processo. Como é de conhecimento, os Realistas, liderados por Charles E. Clark, iniciaram a tradição de estudos empíricos do judiciário, dos litigantes e advogados e conduziu os primários estudos científicos sociais sobre o processo. ${ }^{13} \mathrm{~A}$ era Realista deu origem a uma ideia de pesquisa empírica como um auxiliar às reformas do processo: uma criada da criada, tal como era. Essa tradição foi levada adiante pelo movimento Law and Society nos anos $1960 .{ }^{14} \mathrm{~A}$ atual sociologia crítica do processo dá continuidade e ao mesmo tempo procura remodelar essa tradição.

O interesse dos Realistas em pesquisas empíricas não estava limitado ao processo civil; pesquisas empíricas eram centrais para o programa Realista por razões que transcendem o seu papel no processo. ${ }^{15}$ Além disso, as mudanças no pensamento sobre 0 processo civil que os Realistas iniciaram não necessariamente apontavam, por si mesmas, para pesquisas empíricas mais do que o pensamento clássico teria excluído a empiria. Entretanto, as visões dos Realistas sobre o direito, que questionavam a determinação dos direitos e enfatizavam a inseparabilidade do processo e da substância, ${ }^{16}$ fizeram com que a pesquisa empírica parecesse mais importante do que teria parecido aos teóricos clássicos. E essas visões ajudaram a modelar a agenda dos estudos empíricos que emergiu após o Realismo.

\subsection{A indeterminação dos sujeitos}

O pensamento jurídico clássico presumia que os direitos eram cognoscíveis. Os teóricos clássicos pensavam a doutrina jurídica como inequívoca; eles presumiam que havia um método determinado que poderia ser empregado para identificar a regra correta para qualquer conjunto de fatos dados. Além do mais,

\footnotetext{
13 Para uma discussão completa sobre os estudos iniciais inspirado nos Realistas e o papel de Clark, ver Schiegel, 1979.

14 A pesquisa empírica em litigância por estudiosos da Law and Society é volumosa. Para uma visão geral e bibliografia útil do trabalho até 1980-81, ver o "Special Issue on Dispute Processing and Civil Litigation", publicado na revista Law \& Society Review, volume 391 de 1980-81.

15 Para uma análise mais completa, ver Trubek \& Esser, 1989.

16 Ver infra notas $16-23$ e texto anexo.
} 
os fatos eram pensados como objetivos e questões de fato e de direito eram consideradas distintas. Assim, o processo cumpriria sua função e seria completamente transparente enquanto levasse ao descobrimento dos fatos verdadeiros e aplicação das regras corretas.

O pensamento Realista fez o processo parecer mais importante e ainda mais problemático do que parecia no entendimento clássico. Os Realistas argumentaram que a doutrina jurídica contém respostas alternativas e não raro conflitantes para questões jurídicas, de modo que frequentemente não há uma única resposta certa. ${ }^{17}$ Eles acreditavam que formulações verbais de regras jurídicas e conceitos não poderiam nunca serem precisas e fixas o suficiente a ponto de necessariamente gerar respostas claras para novas questões. ${ }^{18}$ Realistas viram que não havia uma linha clara entre fato e direito, e que a escolha da regra jurídica apropriada somente deveria ser feita depois de uma completa análise da situação fática em disputa. ${ }^{19}$ Finalmente, eles reconheceram que o processo de adjudicação frequentemente, se não sempre, envolve análises contextuais e conjunturais nas quais as questões de política pública devem ser consideradas à luz dos fatos particulares de disputas específicas. ${ }^{20}$

\subsection{Efeitos no pensamento sobre o processo} Revisões do entendimento clássico tiveram um impacto sutil o pensamento relativo à natureza e à importância do processo. Para os Realistas, o processo parecia ainda mais importante do que parecia para os teóricos clássicos, porque era indissociável da substância. O Realismo deixou claro que a adjudicação envolvia fazer o direito (lawmaking), mesmo que isso fosse visto como intersticial. Devido à visão dos Realistas sobre a

\footnotetext{
17 Ver e.g. Llewellyn, 1931.

18 Ver e.g. Cohen, 1935.

19 Ver amplamente a Nota de Harvard: Note, Plausible Pleadings: Developing Standards for Rule 11 Sanctions, Harvard Law Review, 100, 630, 645-47 (1987).

20 A nota de Harvard descreve isso muito bem: "[Os Realistas] acreditavam que as regras legais cresciam das circunstâncias factuais dos casos aos quais eram aplicadas (...) De acordo com os [R] ealistas, os juízes criam novas regras de direito toda vez que eles decidem casos (...) [U]ma vez que o direito é entendido como logicamente indeterminado, a autoridade institucional dos juízes desempenha um papel muito importante na doutrina da decisão judicial (doctrinal decision making) (...) [J]uízes não meramente percebem o direito, eles o criam." Id., nas páginas 646-647.
}

indeterminação dos direitos e à natureza contextual do julgamento jurídico, esse tipo de processo micro de produção do direito (micro-lawmaking) parece ser desejável e não anômalo ou impróprio.

Nesse contexto, a transparência não poderia ser mais o único objetivo do processo. Se cada ação judicial é um micro processo de criação do direito no qual as regras eram definidas e redefinidas à luz de um rico entendimento do contexto social, se os conceitos do fato e do direito não eram categorias objetivas, mas sim definidas uma em relação à outra, e se em cada situação há múltiplas e possíveis regras conflitantes que o tribunal pode se basear, então a linha clara entre substância e processo que o pensamento clássico traçou deveria ser reconsiderada. Uma vez que isso foi feito, o processo começou a parecer tanto mais importante quanto mais complexo do que parecia no pensamento clássico. Não era mais somente uma questão de ajustar a maquinaria para chegar aos fatos verdadeiros e às regras corretas, dado que estas não existiam, ao menos no sentido clássico.

Essa mudança no pensamento teve várias ramificações. Para os objetivos presentes, a mais importante foi enfatizar a utilidade da pesquisa empírica na operação das cortes. 0 pensamento Pós-Realista sobre o processo civil ressaltou a importância que as diferenças em arranjos procedimentais poderiam ter em resultados substantivos. Desde que se aceitou que várias respostas doutrinárias estavam disponíveis e que diferentes descrições "factuais" eram plausíveis, a ciência jurídica Pós-Realista não poderia oferecer a única solução correta contra a qual resultados reais poderiam ser medidos. Nesse contexto, a atenção virou-se para questões do processo e da participação. Em vez de se medir o processo verificando-se se produziu o resultado "correto", o pensamento Pós-Realista tende a avaliar o processo em termos de oportunidades que ele criou para a participação completa dos interesses afetados. A pesquisa empírica pareceu ser uma ferramenta útil, se não indispensável para essa tarefa. Assim, não é surpresa que estudos do processo e de participação floresceram na pesquisa em Direito e Sociedade que começou no período Pós-Realista. ${ }^{21}$

21 A ênfase no processo era aparente na proliferação de estudo sobre o acesso à justiça, um tema fundamental na pesquisa da Law 
Sem dúvida, o estudo clássico nesse gênero foi o amplamente citado artigo "Why the 'Haves' Come Out Ahead". 22 Enquanto que o de certa forma polêmico título do artigo pode sugerir que Galanter estava conduzindo uma análise baseada em classes de tendências substanciais na litigância civil, o estudo de fato é focado na justiça do processo adjudicativo e quase-adjudicativo. Além disso, enquanto Galanter identificou elementos estruturais na prática de litigância e procedimentos que tendiam a favorecer litigantes organizacionais sobre litigantes individuais, ${ }^{23}$ ele pensou que essas barreiras para um processo justo poderiam ser superadas com ajustes no processo civil e por meio da oferta de certos tipos de advocacia subsidiada. ${ }^{24}$

Desta forma, é possível argumentar que o Realismo Jurídico impulsionou uma sociologia do processo civil. Mais do que isso, também pode-se descrever essa sociologia como uma prática crítica, de certo modo. Afinal de contas, era pelo fato de o processo ter se tornado mais saliente e problemático que a pesquisa empírica das operações do processo e seus efeitos parecia tão importante para os estudiosos Pós-Realistas. Contudo, o objetivo dessa prática crítica era muito limitado, ao menos à luz dos desenvolvimentos recentes. Primeiro, muito do trabalho tomou os objetivos e aspirações do sistema procedimental por seu valor de face. Estudiosos reconheceram que as coisas podem não funcionar na prática como esperado, mas aceitaram a visão de que o sistema estava comprometido com seus pretensos objetivos. ${ }^{25}$ Por exemplo, Galanter nunca de fato questionou que, uma vez que foi demonstrado que os que têm (os "haves") de fato saíam na frente, alguém poderia querer fazer alguma coisa com relação a isso. ${ }^{26}$ Do mesmo modo, o estudo

and Society. Ver, e.g., M. Cappelletti (ed.), 1981. Ver também: Cappelletti \& Garth, 1978.

22 Galanter, 1974.

23 Id. nas páginas 119-24.

24 ld. nas páginas 135-44.

25 Para uma formulação desta visão, ver Silvey \& Sarat, 1987; Silvey \& Sarat, 1988. Ver também: Trubek \& Esser, 1989, supra nota 14, nas páginas 14-19.

26 Ver Galanter, supra nota 21, nas páginas 135-144. Os trabalhos da Law and Society Pós-Realista mostram uma fé implícita na viabilidade e precisão do legalismo liberal. Em outras palavras, os valores inerentes do sistema nunca foram questionados; a justiça era vista como um conceito determinado com significados fixos ao invés de uma simbólica construção que poderia ser usada por vários grupos tanto para avançar programas ideológicos, quanto de Wayne Brazil sobre o "discovery abuse", uma das mais veementes críticas empíricas do modo de operação do processo civil produzido nos anos recentes, parece supor que, se podemos demonstrar que a "discovery" está sendo utilizada para objetivos inconsistentes com seus objetivos alegados, reformas virão em seguida. ${ }^{27}$

A segunda característica limitante da sociologia do processo civil Pós-Realista era a tendência de se aceitar a ideia clássica do sujeito autônomo. Embora os estudiosos da Law and Society tenham incorporado todas as críticas dos Realistas sobre o pensamento clássico, essa característica da velha tradição não foi totalmente questionada. Poucos estudos de fato começaram a explorar como advogados manipulavam clientes, ${ }^{28}$ mas de longe era levado em consideração que os sujeitos vêm para o processo com objetivos completamente constituídos sem contaminação pelo contato com instituições jurídicas ou a ideologia jurídica.

\section{Mudanças Teóricas - Questionando o sujeito}

A teoria social e jurídica contemporânea suscitou questões sobre a ideia liberal do indivíduo e do papel do direito no auto empoderamento e, assim, questionou aspectos fundamentais do entendimento Pós-Realista do processo civil que é fundada em tais noções liberais. Esses desenvolvimentos teóricos influenciaram a sociologia crítica do direito, levando estudiosos a fazerem novos questionamentos e articularem novos temas. Duas ideias principais foram centrais nesse processo: a constituição discursiva da subjetividade e a natureza contextual do indivíduo.

O termo "constituição discursiva da subjetividade" se refere à ideia de que o indivíduo não é uma entidade natural independente de relações sociais, mas sim é criado por meio de práticas sociais, ou discursos. Onde o liberalismo clássico situa um indivíduo natural, muitas vertentes no pensamento pós-liberal enfatizam a natureza criada socialmente de nossa subjetividade. Alguns que adotam essa ideia chegam

\footnotetext{
para ignorar completamente exigências de mudança social. 27 Ver: Brazil, 1978.

28 Ver, e.g., Blumberg, 1967, 15-39. Macaulay, 1979.
} 
ao ponto de negar a existência de qualquer coisa que alguém poderia chamar de indivíduo (self). Esta é a posição usualmente associada com o filósofo francês Michel Foucault. ${ }^{29}$ Foucault vê o indivíduo como nada mais do que o resultado do "poder disciplinar". ${ }^{30}$ Para Foucault, não há um eu, mas apenas indivíduos que são simplesmente o produto de várias práticas disciplinares e de discursos. ${ }^{31}$

Temas foucaultianos aparecem na sociologia crítica do processo. Mas a noção de constituição discursiva da subjetividade não é necessariamente limitada à imagem sombria de Foucault do desaparecimento do sujeito. Também é associada com uma outra ideia que pode ser chamada de indivíduo contextual. Alguns teóricos sociais que rejeitam as premissas liberais sobre o sujeito suscitam uma descrição alternativa do sujeito, uma que destaca a importância das relações e dos contextos sociais mais do que o isolamento e autonomia. Autores que postulam o indivíduo contextual criticam a noção liberal dos direitos e com isso a efetivação dos direitos como inconsistente com o auto-empoderamento genuíno. ${ }^{32}$

A ideia de um indivíduo contextual tem muitas raízes e aparece hoje em muitas versões, mas um particular exemplo poderoso e relevante dessa noção aparece nos recentes trabalhos de Roberto Mangabeira Unger. Em um curto volume chamado "Passion"33 e em um extenso tratado intitulado "Politics", ${ }^{34}$ Unger tem desenvolvido um conceito de indivíduo contextual e uma teoria social que objetiva criar as condições para

29 Ver amplamente: M. Foucault, 1977; M. Foucault, 1978; M. Foucault, 1980. Um elemento essencial no trabalho de Foucault é a relação entre poder e conhecimento, que é importante para redefinir o indivíduo como um sujeito obediente. Como o corpo se torna um alvo para novos e redefinidos mecanismos de poder, é ofertado a novas formas de conhecimento. 0 indivíduo pode ser conhecido, descrito, comparado à norma, e então controlado. O discurso jurídico é apenas um discurso entre outros que são parte desse processo de normalização.

30 M. Foucault, 1980, supra nota 28, nas páginas 156, 170.

31 Este argumento é desenvolvido com mais vigor em M. Foucault, 1980, supra nota 28. Ver também. H. Dreyfus \& P. Rabinow, 1983.

32 Ver amplamente Gabel, 1984. Para uma perspectiva similar que critica as fundações Kantianas do liberalismo e dos limites teóricos de uma definição liberal do indivíduo, ver M. Sandel, supra nota 6, nas páginas 14, 50-65, 175-83.

33 R. Unger, 1984.

34 R. Unger, 1987b. o empoderamento de tal sujeito. Para Unger, o indivíduo é uma fonte de infinitas possibilidades, mas essas possibilidades somente podem ser realizadas dentro de contextos - isto é, em relações pessoais e políticas. ${ }^{35}$ Para empoderar o indivíduo contextual, é essencial criar condições de confiança, solidariedade e "plasticidade", ou "revisibilidade institucional"36. Porque o liberalismo falha em captar a natureza contextual da individualidade autêntica, Unger argumenta, ele sublinha os valores negativos da liberdade do constrangimento social enquanto dá menos importância à construção de instituições que fomentem a confiança, a solidariedade e a plasticidade. ${ }^{37}$

Os temas da constituição discursiva da subjetividade e a natureza contextual do indivíduo tem afetado os estudos jurídicos nos últimos anos. Eles podem ser vistos, por exemplo, na bastante debatida (e frequentemente mal compreendida) "crítica dos direitos" do movimento Critical Legal Studies. ${ }^{38}$ Autores que trabalham nessa tradição têm argumentado que o discurso dos direitos presume que indivíduos tem acesso completo e autônomo a um entendimento de seus interesses naturais, dessa maneira ignorando o modo pelo qual práticas sociais e ideologias constroem esses mesmos entendimentos. ${ }^{39}$ Além do mais, a crítica dos direitos presta atenção à natureza relacional e contextual da individualidade, criticando práticas jurídicas que individualizam o conflito e isolam disputas dos contextos sociais e relações nas quais elas estão enraizadas. ${ }^{40}$

Aqueles que aceitam a natureza discursiva da subjetividade e a natureza relacional do indivíduo devem questionar aqueles aspectos da narrativa clássica do processo civil que não foram tocados pelas críticas dos Realistas. Eles são forçados a reconhecer que o sistema jurídico, amplamente concebido, pode contribuir para a constituição do sujeito, ao invés de simplesmente promover (ou frustrar) os fins de um

35 Ver R. Unger, 1984, supra nota 32, nas páginas 5-22.

36 Ver R. Unger, 1987a; R. Unger, 1987b. Ver também R. Unger, 1986. 37 Para um resumo da visão de Unger, ver: Trubek, 1989.

38 Ver, de um modo geral, Gabel, 1984, supra nota 31; Tushnet, 1984. Para críticas da crítica dos direitos, ver Minority Critiques of the Critical Legal Studies Movement, 1987.

39 Ver Gabel, 1984, supra, nota 31; Villmoare, 1985.

40 Ver Gabel, 1984, supra nota 31; Tushnet, 1984, supra nota 37. 
indivíduo pré-constituído e autônomo. Ao mesmo tempo, eles devem confrontar o fato de que o sistema jurídico, como atualmente concebido, pode negar a natureza relacional ou contextual do indivíduo, frustrando, deste modo, a realização da individualidade autêntica. Essas ideias amplas reforçam a tradição acadêmica aqui chamada de sociologia crítica do processo civil. Elas têm gerado uma série de novos temas. A próxima parte desse artigo enuncia esses temas.

\section{Temas emergentes na sociologia crítica do processo}

Afetados por esses desenvolvimentos da teoria social, os sociólogos do direito têm articulado uma série de críticas à litigância, ao processo e à pesquisa social em si mesma. Elas são: (1) a negação do indivíduo autêntico; (2) a construção jurídica da realidade social; (3) a vitimização da vítima por meio do direito; (4) a alternativa comunitária e a crítica da adjudicação; (5) a crítica da ADR e dos discursos de necessidade; e (6) a discursividade do conhecimento social.

\subsection{Negação do indivíduo autêntico}

Como discutido anteriormente, o pensamento Pós-Realista aceita a noção clássica que o objetivo do direito civil substancial é empoderar o sujeito. Como a criada para o direito substantivo, o processo compartilha esse objetivo. ${ }^{41} \mathrm{O}$ primeiro tema na nova literatura é o questionamento desta noção.

Este tema emerge com claridade nos recentes escritos sobre as relações entre advogado-cliente. A sociologia do direito tem por muito tempo se preocupado com este tópico. Ela reconheceu que há conflitos potenciais entre os interesses dos advogados e dos clientes. Mas a literatura tendeu em focar nos meios pelos quais esse conflito pode ser reduzido ou eliminado ao se empoderar o cliente de forma que o advogado irá realizar objetivos do cliente. ${ }^{42} \mathrm{~A}$ nova literatura explora um aspecto profundo e mais preocupante da relação advogado-cliente: o modo pelo qual os advogados criam fins de forma que os clientes terminam almejando - ou ao menos aceitando - o

41 Ver supra notas 20-27 e texto que as acompanha. 42 E.g. D. Rosenthal, 1977. que o sistema está preparado para entregar. ${ }^{43}$

Certamente, a noção de que advogados manipulam clientes para que eles aceitem as ideias dos advogados como desejáveis ou factíveis não é realmente nova. Na tradição da Law and Society, este tema remonta, pelo menos, ao estudo clássico de Abraham Blumberg do modo pelo qual defensores públicos "esfriam" réus criminais. ${ }^{44}$ Este tema também aparece no estudo de 1979 de Stewart Macaulay sobre advogados e proteção consumerista, que mostra como as próprias visões políticas e sociais dos advogados e seus interesses econômicos os levaram a redefinir queixas trazidas a eles por seus clientes consumidores. ${ }^{45}$ Mas essa ideia tem sido reapresentada em tons mais sóbrios.

Talvez a melhor expressão desse tema na nova literatura pode ser encontrada no estudo de Sarat e Felstiner sobre advogados de divórcio e seus clientes. ${ }^{46} \mathrm{Ba}$ seada em observações da interação advogado cliente e entrevistas aprofundadas, este estudo demonstra as complexas e sutis maneiras com que um advogado de divórcio convence um cliente a deixar de lado sentimentos profundamente emotivos e desejos de uma reivindicação moral para que o cliente possa aceitar a resolução que o advogado acredita que é factível. ${ }^{47}$ 0 estudo foca em detalhes nas práticas linguísticas empregadas pelos advogados para reconstruir a subjetividade do cliente. ${ }^{48}$

O estudo de Sarat e Felstiner ilustra o tema de que a litigância pode constituir uma negação de uma subjetividade autêntica, mas talvez essa afirmação simplifique demais o complexo argumento encontrado nessa rica descrição etnográfica. Os autores na realidade descrevem o processo de "construção jurídica do cliente", no qual elementos da subjetividade do cliente são divididas entre um "indivíduo emocional" e um "indivíduo jurídico" ${ }^{9}$. Eles não invocam expressamente noções de autenticidade ou negação, ainda

43 Ver Sarat \& Felstiner, 1986.

44 Blumberg, 1967, supra nota 27, na página 28.

45 Macaulay, 1979, supra nota 27, nas páginas 120-43, 151-66. 46 Sarat \& Felstner, 1986, supra nota 42

$47 / d$.

48 /d. nas páginas 94-96.

49 /d. nas páginas $96,116-25$. 
que seu artigo note que o advogado "expressa a indiferença do direito em relação àquelas partes do indivíduo que podem ser as mais salientes no momento do divórcio". ${ }^{50}$

\subsection{O direito e a Construção da Realidade Social}

Nos estudos das relações diretas ente advogados e clientes, a nova sociologia do direito revela uma preocupação com os modos pelos quais o contato com o processo jurídico molda o indivíduo (self), mais do que realizar os fins de uma subjetividade preexistente. ${ }^{51} \mathrm{~A}$ ideia que o discurso jurídico constitui indivíduos pode também ser vista em estudos que demonstram que as percepções individuais do direito e de seus próprios interesses não antecedem o contato com o sistema jurídico, mas são construídas por meio desses contatos. Esta ideia aparece em uma forma ainda mais ampla em afirmações de que todas as relações sociais, mesmo aquelas não afetadas diretamente pelo contato com o sistema jurídico, são moldadas ou constituídas pelo discurso jurídico ou pela ideologia. ${ }^{52}$

O tema da construção jurídica da realidade social surgiu primeiro na literatura de transformação de disputas (disputes transformation). Esta literatura trata do meio pelo qual as disputas são definidas e modificadas à medida que percorrem suas trajetórias. Dois conceitos surgiram dessa literatura que influenciaram trabalhos posteriores: a ideia de "refraseamento", 53 (rephrasing) de Mather e Yngvesson, e a análise feita por Felstiner, Abel e Sarat de "nomeando, culpando e reivindicando" (naming, blaming, claiming). ${ }^{54}$ Estudiosos reconheceram que o processo pelo qual uma disputa surge envolve três estágios problemáticos: nomeando uma queixa, culpando um determinado ator pelo prejuízo e reivindicando algum remédio. ${ }^{55}$ Cada um desses estágios é construído socialmente; não há ideias inatas que podem ser empregadas para negociar desde a percepção do prejuízo a uma cer-

50 /d. na página 132

51 Ver supra notas $42-49$ e texto que as acompanha.

52 Trubek \& Esser, 1989, supra nota 14, nas páginas 20-34.

53 Mather \& Yngvesson, 1980-81.

54 Felstiner, Abel \& Sarat, 1980-81.

55 ld. ta reivindicação. ${ }^{56}$ Ideias predominantes no discurso jurídico moldarão como indivíduos reagem a várias possibilidades e os contatos institucionais canalizarão os comportamentos individuais. ${ }^{57}$ Além disso, em cada estágio do processo a disputa será refraseada reformulada em um discurso institucional que pode ser muito diferente da compreensão inicial dos participantes da disputa. ${ }^{58}$

O reconhecimento de uma natureza socialmente construída do processo de transformação de disputas levou estudiosos a dar atenção aos micro encontros nos quais o sentido de uma disputa é negociado. Estudos descrevem como ideologias sobre o que é o direito e o que ele faz são utilizadas por advogados e funcionários da justiça para dissuadir clientes e partes de certas escolhas e para aliviar o sofrimento causado por expectativas reduzidas e esperanças frustradas. Estudos de Merry e de Yngvesson sobre funcionários da justiça de primeira instância, por exemplo, mostram como tais oficiais justapõem ideologias oficiais sobre o direito como um sistema de proteção de direitos com noções das "ruas" do direito ("street" notions of law) como uma arena na qual a personalidade e o poder desempenham um papel dominante. ${ }^{59}$ Os estudos de Sarat e Felstiner sobre a relação entre advogados e clientes mostram uma abordagem similar. Em sua análise sobre os modos pelos quais advogados de divórcio procuram diminuir a expectativas de seus clientes sobre como eles podem obter por meio do direito, os advogados se valem de uma imagem cínica de como o direito é manipulável, frio e arbitrário. ${ }^{60}$

56 Id. nas páginas 637-39.

57 Id. nas páginas 639-49.

58 Id. nas páginas 637-39, 651; Mather \& Yngvesson, 1980-81, supra nota 52 , nas páginas $818-21$.

59 Merry, 1985.

60 Sarat \& Felstiner, 1986, supra nota 42, nas páginas 99-116. “[A] descrição do advogado de como juízes lidam com ordem judiciais sugerem um alto nível de desatenção e de práticas rotineiras. Juízes assinam ordens sem lê-las para satisfazer 'pessoas que realmente precisam dessas coisas'. Enquanto se diz que o juiz ignora a substância da ordem, ele presta atenção ao advogado ou escritório de advocacia que requer isso. O processo legal é apresentado, deste modo, como resposta mais à reputação do que de mérito substantivo. Portanto, o cliente é introduzido a um sistema que é apressado, rotineiro, personalíssimo e propenso a acidentes" Id. na página 100. 
Os recentes trabalhos sobre a transformação das disputas lidam diretamente com a litigância e mostram como contatos diretos com o advogado e com o sistema jurídico transformam ou criam o que os indivíduos procuram e esperam do sistema de justiça civil. ${ }^{61}$ Mas o tema da construção jurídica da realidade social vai além de observações do impacto de contatos reais com advogados e tribunais na subjetividade. Tal tema é ampliado de formas nas quais o discurso jurídico penetra na vida cotidiana, afetando a definição mesma de relacionamentos e de conflitos.

Desta forma, práticas e ideias associadas ao direito e às instituições jurídicas podem ser vistas como estruturas de sentido que irradiam durante a vida social e servem como parte do material de que as pessoas se utilizam para negociar seus entendimentos dos eventos e relacionamentos cotidianos. ${ }^{62}$ As estruturas do significado incrustadas no discurso jurídico incluem noções muito básicas de quais tipos de relacionamentos são possíveis e desejáveis. Por exemplo, noções legais de posse e propriedade formam parte do material utilizado para explicar porque algumas pessoas - aquelas que têm ou gerenciam indústrias, escolas e outras organizações - têm poder legítimo sobre outros. ${ }^{63}$ Noções jurídicas de como pessoas em relações íntimas devem lidar umas com as outras afetam como as pessoas definem o que elas entendem por uma família. O discurso jurídico inclui métodos sutis de valorar certos tipos de comportamento, como esforços instrumentais para bens materiais e de desvalorizar outros.

Quando estudiosos dizem que os discursos jurídicos constituem a vida social, eles não necessariamente querem dizer que o direito é um corpo rígido de noções intimamente ligadas e valoradas que são transmitidas a partir de elevadas produções ideológicas de pensamento jurídico de alguma maneira misteriosa aos pensamentos e sentimentos de todos. Na realidade, alguns estudiosos que escrevem sobre o modo no qual a ideologia jurídica molda a percepção social e direciona o comportamento social falam como se houvesse uma ideologia jurídica relativamente coesa

61 Ver e.g., id nas páginas 107-08.

62 Gordon, 1982.

63 Fischl, 1986. e amplamente difundida, ${ }^{64}$ mas outros veem o processo como extremamente frouxo e maleável. ${ }^{65}$

O posicionamento que um estudioso adota com relação à questão da maleabilidade pode depender das origens sócio teóricas da noção de construção social que um determinado estudioso adota. O tema da construção legal do cotidiano se vale de vários corpos da teoria social, incluindo antropologia crítica, estruturalismo neomarxista, Estudos Críticos do Direito (Critical Legal Studies) e teoria literária pós estruturalista. Todas essas teorias sociais veem o direito como um dos vários discursos de poder ou estruturas ideológicas que reforçam relações de poder e condições de hierarquia. Elas diferem, contudo, em suas visões de como o discurso estrutura as relações. Para alguns na ponta do espectro pós estruturalista, o processo é altamente difuso e ad hoc; atores utilizam fragmentos e pedaços de vários discursos enquanto negociam relações cotidianas. ${ }^{66} \mathrm{Na}$ outra ponta do espectro, as narrativas estruturais neomarxistas veem a ideologia como firmemente enraizada em estruturas de poder bem organizadas e transmitidas por meio de séries de práticas mutuamente reforçadas e hegemônicas. ${ }^{67}$

A ideia que o entendimento cotidiano incorpora visões produzidas e reproduzidas pelos discursos sobre o direito é inspirada em vertentes díspares da teoria social contemporânea que retratam a ideologia jurídica de forma diferente. Não obstante, todas essas teorias enxergam o direito como um de vários discursos ou ideologias que reforçam relações de poder e condições de hierarquia. Onde a visão liberal vê o direito como um escudo para a autonomia e como um instrumento de realização de projetos autênticos, essas teorias sociais críticas enxergam ideias jurídicas e instituições como parte de um processo complexo por meio do qual o indivíduo é realmente constituído pelas relações sociais e discursos. De uma forma ou de outra, todas defendem que essa construção social do indivíduo por meio da ideologia e linguagem suprime o completo potencial do indivíduo. ${ }^{68}$

64 Ver Hunt, 1985. Ver também: Trubek, 1984; Trubek \& Esser, 1989, supra, nota 14, na página 27. 65 Ver Coombe, 1989.

66 Ver id. nas páginas 91-93.

67 Ver Hunt, 1985, supra, nota 63, nas páginas 13-19.

68 Ver, e.g., Gabel, 1984, supra, nota 31. 


\subsection{O direito e a Vitimização da Vítima}

O terceiro tema na nova literatura é "a vitimização da vítima" pelo direito. Este termo vem de um recente estudo do direito antidiscriminação elaborado por Kristin Bumiller sob o título "The civil Rights Society" "69. Esse livro, que examina como vítimas de discriminação experimentaram o direito e seus contatos com a litigância, incorpora vários dos temas que emergem na sociologia crítica do processo. Bumiller explora conflitos entre o uso do direito e a realização do indivíduo (self), ${ }^{70}$ mostra como o direito é utilizado no discurso do dia a dia para construir a identidade ${ }^{71}$, e reconhece que o modo pelo qual o conhecimento social é construído afeta a natureza da sociedade em que vivemos. ${ }^{72}$

O argumento central de Bumiller, entretanto, é que "o direito antidiscriminatório serve para reforçar a vitimização dos seus 'beneficiários."”73 Ela reconhece que o direito pode falhar em responder às demandas do sujeito, como Sarat e Felstiner sugerem; ela também reconhece que o discurso jurídico desempenha um papel fundamental na construção de nossas identidades, assim como argumentam os autores da ideologia jurídica. Mas Bumiller vai além: Em sua crítica ao direito antidiscriminatório ela afirma que, na operação atual, esse corpo de direito e os processos com ele associados podem ter um efeito direto oposto aos alegados propósitos do direito. Se o direito antidiscriminatório vitimiza seus supostos beneficiários, não somente falha em prevenir a discriminação; mas também a perpetua. ${ }^{74}$

69 K. Bumiller, 1988.

70 ld. na página 109.

71 ld. na página 33.

72 Id. na página 32-38. Bumiller explicitamente procura um método da ciência social o qual releva a perspectiva da vítima e, assim o fazendo, cria a possibilidade de transformação social. Concluindo a parte metodológica do livro, ela diz: "Este trabalho é motivado pelo desejo de fazer a pesquisa em ciência social mais responsiva aos problemas de opressão social e de abatimento da realidade do dia a dia (...) Espero que a interpretação dessas realidades sociais possa criar uma visão libertadora de possibilidades alternativas". Id. na página 38. Para uma visão completa deste tema, aqui chamado de discursividade do conhecimento social, ver infra notas 107-13 e textos que as acompanham.

73 K. Bumiller, 1988, supra nota 68, na página 39.

74 É útil notar a diferença entre a crítica de Bumiller de leis antidiscriminatórios e análises mais convencionais da falha de reformas legais feitas pelos estudiosos da Law and Society. Como Sarat apontou, um dos produtos básicos da pesquisa da Law and Society
Bumiller chega a essa conclusão radical por meio de um rico e complexo argumento que vai bem além de questões relacionadas ao processo, mesmo se este for definido de forma mais ampla. 0 estudo, contudo, contribui diretamente para o nosso entendimento das visões sociais que subjacentes ao pensamento processual. 0 estudo de Bumiller desafia algumas das premissas reinantes sobre litigância e processo. Ela possui uma crítica devastadora da psicologia implícita usada em muitas reflexões sobre o processo e ela coloca em questionamento premissas de Realistas e Pós-Realistas de que mecanismos processuais mais efetivos podem, ao melhorar o acesso à justiça, facilmente garantir que direitos serão efetivamente realizados.

O estudo de Bumiller começou com a observação de que pessoas que percebem a si próprias como discriminadas são muito menos frequentes que outras que percebem ameaças tanto para reclamar, quanto para procurar reparação jurídica. ${ }^{75} \mathrm{Em}$ sua pesquisa, ela buscou uma explicação para essas diferenças. Seu método era explorar a psicologia de vítimas de discriminação por meio de entrevistas profundas. ${ }^{76}$ Essas entrevistas levaram Bumiller a desenvolver uma descrição da psicologia das pessoas afetadas pela discriminação que conflita diretamente com a psicologia implícita no pensamento predominante sobre o processo civil.

Como previamente sugerido, a tradição predominante parte da premissa de que sujeitos autônomos são instados a obter conhecimento de seus direitos e para buscá-los por meio da litigância, se necessá-

é o estudo de lacunas, que mede a lacuna entre os objetivos da política pública legal e dos resultados que a política pública produz. Sarat, 1985. Tais estudos reconhecem que as reformas legais podem falhar em atingir seus objetivos, tais como a eliminação de discriminação racial, mas eles não questionam o compromisso da ordem jurídica a esses objetivos. A análise de Bumiller da lei de antidiscriminatória, por outro lado, desafia esse compromisso. Ela explicitamente rejeita a abordagem do estudo de lacunas para o estudo de leis de direitos civis. K Bumiller, 1988, supra nota 68, nas páginas 25-26. Ao contrário, ela enfatiza as maneiras positivas em que a existência de leis antidiscriminatórias enfatizam a vitimização. Id. nas páginas 2, 39. Ainda, ela sugere, legislações protetivas podem resultar que perpetuação de padrões de conduta que mantém práticas discriminatórias. Ver id. nas páginas 110-11.

75 K. Bumiller, 1988, supra nota 68, nas páginas 26-30. Essas observações foram feitas a partir de uma pesquisa de abrangência nacional conduzida pela Civil Litigation Research Project. Para um relatório completo da pesquisa, ver Miller \& Sarat, 1980-81. 76 K. Bumiller, 1988, supra nota 68 , nas páginas 29-30. 
rio. Nessa visão social, a litigância é um ato natural por meio do qual o indivíduo afirma sua vontade. Este relato individualista e baseado na vontade era central no pensamento clássico e não foi modificado significativamente pelos Realistas. O Realismo reconheceu que direitos podem ser incertos, e que pode haver barreiras econômicas e institucionais para a litigância, mas os Realistas não questionaram que pessoas podem ser motivadas a procurar direitos que foram estabelecidos pelo direito e por isso conhecidos publicamente.

Em sua análise das motivações das vítimas para usar ou não usar a lei de antidiscriminação, Bumiller argumenta que há fortes barreiras psicológicas que impedem que vítimas de discriminação percebam atos discriminatórios como violações de direitos cognoscíveis, assim como as impedem de buscar esses direitos mesmo percebendo a violação. Ela nota que para se tornar um denunciante em uma queixa antidiscriminatória, a pessoa deve afirmar que foi vitimizada. ${ }^{77}$ Isso é, o verdadeiro ato de se utilizar do direito demanda que haja a admissão do rótulo de "vítima" de ações proibidas. Mas, ela sublinha, muito nas vidas das pessoas estudadas faz com que elas queiram evitar usar a "máscara de vítima". ${ }^{78}$ A classe de pessoas alegadamente protegidas pelas leis antidiscriminatórias é sujeita a ataques permanentes em sua identidade pelo racismo, sexismo, e outras formas de hostilidade. ${ }^{79}$ Para lidar com essas ameaças, Bumiller postula, pessoas que estejam em determinada classe supostamente protegida desenvolvem o que ela se refere como uma "ética da sobrevivência", que marca sua capacidade de lidar com situações injustas. ${ }^{80}$ Reivindicar a vitimização publicamente, como o direito demanda, põe em risco o senso de controle que as pessoas nessas situações deduzem dessa ética. ${ }^{81}$

Bumiller não afirma que esta estratégia de sobrevivência é a única razão pela qual vítimas podem não ser capazes de ver as suas próprias situações como violações de direito. O outro lado do quadro é o seu medo do direito e do poder das organizações em face das quais elas teriam que reclamar seus direitos. 0

77 Id. na página 99.

78 Id. nas páginas 62-64.

79 ld. na página 84 .

80 ld. nas páginas 78-97.

81 ld. nas páginas 93-95. direito parece estranho e incerto e seus oponentes fortes e informados. Para se utilizar do direito, elas devem apresentar a si mesmas como vítimas, com isso desistindo de uma identidade própria que as permitiu lidar com isso. Mas esse sacrifício não garantirá sucesso; ao contrário, elas frequentemente pensam que perderão em juízo mesmo se acreditarem profundamente que uma injustiça aconteceu. 0 medo dessas pessoas de perder o controle excede de longe suas esperanças de reivindicação por meio do direito. Assim, Bumiller conclui:

Os resultados de minhas entrevistas mostram que pessoas que experimentaram tratamento discriminatório resistem ao engajamento em táticas jurídicas pelo motivo de que temem o poder do direito de perturbar suas vidas cotidianas. Ao mesmo tempo, elas são cínicas sobre o poder do direito de fato ajuda-las a manter seus direitos, sua moradia, e outras oportunidades que elas podem demandar. Elas temem que, se elas procurarem uma solução jurídica, elas não irão melhorar suas posições e perderão controle de uma situação hostil. Esses entrevistados também sentiram que procurar seus diretos não iria fazer com que expressassem seu senso de dignidade, pois iria força-las a justificar seus méritos contra um oponente mais poderoso. 82

Bumiller demonstra que o direito ameaça a dignidade e envolve o risco de se perder um senso de autonomia e controle, mas ela ainda relata um traço a mais de cinismo - a crença de que uma pessoa não apenas perderá sua individualidade autêntica se adentrar no sistema jurídico, como ainda não ganhará nada em retorno pois o direito não tem poder. Assim, Bumiller é crítica em relação ao modo pelo qual funciona toda a estrutura dos direitos civis. Ela argumenta que o sistema que força a vítima de discriminação a se tornar uma vítima do processo legal para remediar os males originais é um sistema que não pode dar certo. De fato, as vítimas que ela descreve em uma situação "Catch-22" clássica: elas somente podem restaurar a dignidade que perderam por meio da discriminação submetendo-se à indignidade do sistema jurídico. Porque é claro que apenas alguns poucos (ou alguns desaviados) o farão, ela sugere que o direito sempre falha em alcançar

82 Id. na página 109. 
seus objetivos ostensivos. ${ }^{83}$ Finalmente, a inutilidade prática da promessa coloca em dúvida a sinceridade da promessa em si. Se o sistema legal fosse realmente interessado em fazer cessar a discriminação racial, de idade e de gênero, teria forçado as vítimas a situações kafkianas que nos descrevem as histórias dos entrevistados de Bumiller? Aqueles que aceitam o argumento desse estudo não imaginarão que alguns dispositivos processuais servirão para curar falhas fundamentais para as quais ela apontou.

\subsection{A Alternativa Comunitária e a Crítica da Adjudicação}

A literatura crítica discutida até agora lida principalmente com a construção discursiva dos sujeitos. Estudos sobre a interação entre advogados e clientes, a ideologia do direito no cotidiano e a vitimização da vítima desafiam a visão liberal do sujeito autônomo. Mas os estudiosos da Law and Society também têm contribuído no desenvolvimento de uma perspectiva mais comunitária da litigância. Ao fazê-lo, têm contribuído para o entendimento das implicações que a ideia de um indivíduo contextual (contextual self) pode ter para o processo civil.

Na realidade, esses esforços não se elevaram a uma verdadeira teoria comunitária de justiça e tampouco fizeram com que reformas jurídicas se espraiassem. Apesar disso, os estudiosos da Law and Society articularam algumas críticas à adjudicação que refletiam o descontentamento com as ideias liberais sobre a relação entre o direito e a sociedade e o trabalho deles de fato emprestou algum suporte a esforços radicais para se desenvolver novos métodos para se lidar com disputas.

Há dois termos na literatura da Law and Society que sugerem a presença de preocupações comunitárias: (1) preocupação com o impacto do processamento de disputas judiciais nas relações sociais; e (2) interesses em fontes comuns de ordens normativas.

Uma grande preocupação dos trabalhos da Law and Society sobre a litigância foi o medo de que a adjudicação é nociva às relações sociais de longo prazo. ${ }^{84}$

83 Ver supra notas 72-73 e textos que as acompanham. 84 Entre os fatores que geraram essas preocupações estão os achados de antropologistas do direito a respeito de modelos de disputas em sociedades não-ocidentais. Esses modelos, acreditava-se, diferenciavam-se da abordagem do processo civil em sociedades
Os estudos da Law and Society realçam uma série de características da adjudicação que poderiam tornar difícil às partes continuar as suas relações sociais se elas tiverem que ir ao judiciário para resolver disputas internas aos relacionamentos. Entre esses estavam: o aspecto do vencedor-leva-tudo das medidas civis de proteção, nas quais geralmente uma parte deve ganhar tudo, enquanto a outra parte perde tudo; a estrutura do sistema adversarial, que encoraja cada lado a levar seu caso até o fim; e o olhar retrospectivo que caracteriza a adjudicação, que se volta mais para resolver assuntos do passado do que para procurar maneiras de manter relações no futuro. ${ }^{85}$ Por conta desses aspectos da adjudicação, as pessoas, em suas relações de longo prazo, que venham a ter disputas podem ter que escolher entre ir ao judiciário e sacrificar relacionamentos valiosos ou evitar as cortes e assim ter negado um fórum para expressar sua insatisfação. ${ }^{86}$

O segundo tema comunitário envolve o uso de normas extraídas de espaços comunitários para se resolver disputas. Críticos de instituições jurídicas formais entendem que a justiça seria melhor servida se as normas empregadas nas disputas judiciais fossem extraídas das comunidades nas quais as pessoas vivem suas vidas. Desse modo, comunidades seriam fortalecidas e as disputas seriam manejadas adequadamente. ${ }^{87}$

Um projeto institucional reflete ambas preocupações: o esforço de se desenvolver mediação baseada nas comunidades para muitas das disputas. ${ }^{88}$ Esse movimento de curta duração procurou criar um outro tipo de justiça. Ao se utilizar de mediação ao invés de adjudicação, o projeto procurou encorajar a preservação de relações conturbadas. Ao recrutar mediadores da própria comunidade, procurou fortalecer instituições comuns em uma sociedade cada vez mais atomística.

ocidentais. Por exemplo, reportando-se na operação de uma corte em Zapoteca, México, Laura Nader notou que entre as características das disputas zapotecas estavam soluções de compromisso e considerações sobre a relevância das redes de relações sociais, características que não são normalmente associadas com modelos de adjudicação ocidentais. Nader, 1969.

85 Ver Silvey \& Sarat, 1989. Ver, de modo geral, Yngvesson, 1985. 86 Silvey \& Sarat, 1989, supra nota 84, na página 454.

87 Isso era um ideal implícito na literatura da antropologia do direito. Ver, e.g., Nader, 1969, supra nota 83. Ver também Galanter, 1981. 88 Para um relatório completo, ver Wahrhaftig, 1982. 
A crítica da justiça formal e o interesse pela mediação comunitária refletem uma visão do sujeito e da sociedade bem diferente do individualismo liberal que ainda domina o pensamento mainstream sobre processo civil. Com efeito, essa visão alternativa nunca foi completamente desenvolvida. A preocupação da academia sobre os impactos da adjudicação nas relações sociais não levou a se repensar os ideais do individualismo jurídico. Os estudiosos da Law and Society, de modo geral, estavam satisfeitos em observar que as preocupações relacionais podem explicar alguns padrões de uso ou não uso do Judiciário, enquanto que os proponentes da mediação comunitária estavam preocupados com reformas locais em escalas pequenas, não promovendo transformação social. Além disso, até mesmo a mais modesta proposta de reforma que surgiu dessa era falhou em grande medida e o movimento da mediação comunitária foi engolido pelos movimentos de ADR institucionalizadas dentro do próprio judiciário. ${ }^{89}$

Não obstante, esses esforços modestos certamente apontam para longe do modelo individualista de justiça que ainda prevalece no pensamento mainstream, sugerindo o surgimento de dúvidas sobre as noções clássicas da individualidade autônoma. De fato, em uma discussão recente do movimento para criar alternativas à adjudicação, Robert A. Baruch Bush argumenta que, dentro deste movimento, pode-se descobrir uma "visão de comunidade ou relacional, na qual o maior bem é a conexão do próprio indivíduo com outros em relações interpessoais e comunitárias." ${ }^{90}$ Bush nota, entretanto, que essa visão é apenas uma de uma série de visões encontradas no movimento da ADR, e que até agora não foi adequadamente desenvolvida. ${ }^{91}$

\subsection{A crítica da ADR e os discursos de necessidade}

Os estudos da Law and Society, entretanto, não buscaram desenvolver a visão comunitária latente na

89 Silvey \& Sarat, 1989, supra nota 84, nas páginas 455-57. Nota do Tradutor: ADR se refere às Alternative Dispute Resolution.

90 Bush, 1989. Bush vê todo o movimento da ADR como uma potencial mudança em direção a uma visão relacional, mas receia que a visão comunitária pode ser oprimida por outras abordagens. Id. nas páginas 378-79.

91 ld. na página 379. crítica da justiça formal. Por razões complexas, a ênfase na literatura recente tem se deslocado para uma crítica do próprio movimento da ADR. Esta é uma rica literatura, na qual várias questões são perseguidas. ${ }^{92}$ Apenas uma é aqui mencionada: a crítica do uso de um discurso de ciência comportamental de necessidade como uma justificação para a ADR. Nos anos recentes, foi sugerido que as ciências comportamentais oferecem um recurso que pode ser utilizado para solucionar certos tipos de disputas, especialmente disputas conjugais, melhor do que seriam resolvidas por meio da adjudicação. ${ }^{93} \mathrm{O}$ argumento para o uso destas técnicas de ADR como mediação em divórcios tem encontrado fortes críticas na comunidade da Law and Society. Essa literatura levanta mais uma vez a questão da constituição discursiva da subjetividade.

Os discursos de necessidade, que estão sob ataque crítico, são baseados em uma redefinição do indivíduo e se opõem a noções liberais clássicas. Mas o indivíduo que emerge dessa ligação entre ADR e ciências comportamentais é tanto dependente quanto descontextualizado. Por esta razão, sociólogos críticos do direito têm desafiado as justificações da ciência comportamental da ADR. ${ }^{94}$

Aos olhos dos críticos, alguns proponentes da ADR querem redefinir o sujeito jurídico como uma fonte de necessidades, não um portador de direitos. Como Silbey e Sarat notaram, "[n]a mudança de [de direitos] para necessidades, ao sujeito jurídico é dada uma característica humana mais complicada e rica. Contudo essa característica permanece a alguma distância de si mesmo e, como resultado, apresenta uma noção incompleta de necessidades 'reais'" 950 novo sujeito definido paradoxalmente é radicalmente dependente, ainda que extraído, do contexto social. De forma resumida, este sujeito não possui um idioma com o qual se lida com questões inegociáveis.

Esses críticos parecem estar procurando por uma visão contextual do indivíduo. Não obstante, diferentemente de alguns estudiosos mais anteriores da Law

\footnotetext{
92 Ver, e.g., Wahrhaftig, 1982, supra nota 87 (dois volumes). 93 Ver, de um modo geral, Milne \& Folberg, 1988.

94 Silbey \& Sarat, 1989, supra nota 84, nas páginas 470-96.
} 95 ld. na página 491. 
and Society, eles veem a ADR em termos negativos. A revisão do indivíduo implícito na mudança para o discurso de necessidade, eles temem, pode ser pior do que a visão liberal que substitui. Essa crítica da ADR tem duas dimensões. A primeira desafia o modo pelo qual processos informais alteram as questões que o direito propõe. Então, é sugerido que a ADR tem mudado as fundações epistemológicas do direito. Como resultado, "[d]ebate sobre direitos não é de modo algum deslocado; é, entretanto, transformado e domesticado de certa forma, em face dos discursos de interesses e necessidades". ${ }^{96}$ A mudança de reivindicação de direitos para a satisfação de necessidades modifica o modo pelo qual os conflitos são resolvidos. Novos modos de expressar e realizar as necessidades são valorizados, e tudo se torna um problema de personalidade; como alterar, modificar e moldar o comportamento se tornam as questões chave. ${ }^{97}$ Ao mesmo tempo, as necessidades se tornam reificadas e vem a refletir alguns componentes essenciais da natureza humana; elas assim incorporam alguma essência universal que todos podem reconhecer e compartilhar. ${ }^{98} \mathrm{O}$ problema com essa mudança epistemológica é que uma autoridade diferente e, em muitos casos, oculta, é criada para e por atores específicos no sistema legal, cujo trabalho é servir as necessidades. Uma nova e insidiosa forma de controle é representada nessa microfísica do poder. ${ }^{99}$

O segundo elemento de crítica foca mais nas transformações dos resultados associados com a mudança para a ADR. Enquanto que o primeiro elemento enfatiza as mudanças sutis de poder dentro do direito associadas ao discurso de necessidade, o segundo foca em quem ganha e quem perde nesses novos sistemas. O segundo elemento da crítica tem se centrado em mediações em divórcios, um dos mais significantes resultados do movimento de ADR.

Talvez a voz mais poderosa na crítica dos efeitos da ADR e dos discursos de necessidade é a acadêmica de direito de família Martha Fineman. ${ }^{100}$ Fineman compartilha com os sociólogos críticos uma preocupação

96 Id. na página 497 (nota de rodapé omitida).

97 Id. nas páginas 490-96.

98 Id. nas páginas 492-94.

99 Ver M. Foucault, 1977, supra nota 28, na página 139. 100 Fineman, 1988. sobre como o discurso comportamental terminou substituindo a análise de direitos, mas ela relaciona isso a uma série de preocupações bem concretas - o impacto dessas mudanças em mães divorciadas. ${ }^{101} \mathrm{O}$ argumento de Fineman em síntese é de que a retórica da ciência comportamental dos assistentes sociais veio a dominar a forma de tomada de decisão jurídica, construindo, desta forma, um enclave hegemônico no qual os assistentes sociais podem apresentar seus próprios interesses profissionais. $\mathrm{O}$ argumento sugere que, assim como Silbey e Sarat, ${ }^{102}$ ela teme que a reconstrução do direito pelos discursos de necessidade possa permitir um mapa do comportamento ainda mais refinadamente controlado. ${ }^{103} \mathrm{O}$ que torna o argumento de Fineman particularmente convincente é que ela mostra como essa situação é de fato uma tragédia para várias mães divorciadas.

Uma vez que é atribuído um papel relativamente menor no processo de divórcio sob o sistema de faltas (fault system), assistentes sociais na era do divórcio sem falta (no-fault divorce) redefiniram o divórcio como uma crise emocional. ${ }^{104}$ Vendendo a si mesmos como especialistas na administração das emoções e reconciliação terapêutica, eles têm efetivado mudanças dramáticas no processo de divórcio; em particular, eles têm sido atores fundamentais na redefinição dos modelos de custódia das crianças do "melhor interesse da criança" para a guarda compartilhada. ${ }^{105}$ O divórcio, antes um evento potencialmente emancipatório para as mulheres, se torna uma condição de dependência continuada por causa da demanda de que relacionamentos se mantenham entre os divorciados. O poder de discursos dominantes de profissões auxiliares mantém o status jurídico indeterminado de mães e filhos ao enfatizar a necessidade de se manter a família junta, ao menos simbolicamente, se não concretamente.

A visão de Fineman da mediação em divórcio faz com que o momento utópico na ADR pareça distorcido. Em vez de lidar com a experiência concreta do indivíduo definido pelo contexto, a profissão dos assis-

101 ld. nas páginas 729-30.

102 Silbey \& Sarat, 1989, supra nota 84, nas páginas 490-96. 103 Fineman, 1988, supra nota 99, nas páginas 733, 744-60.

$104 / d$.

105 Id. nas páginas 731-35, 740-44. 
tentes sociais e o processo de mediação tem ajudado a criar uma série de ficções em que muitos querem acreditar: homens e mulheres têm interesses e habilidades parentais iguais; relacionamentos nunca devem terminar acrimoniosamente, podem ser sempre trabalhados; e homens e mulheres são iguais em termos econômicos e simbólicos. ${ }^{106}$ Não obstante o resultado dessas ficções é de que o discurso "tem criado mais do que refletido a realidade". ${ }^{107}$ O que o artigo de Fineman indica é que a experiência de muitos indivíduos não é compatível com essas ficções. De fato, o legado da ADR é a circulação de certos tipos de discurso que engrandecem o compartilhamento, o cuidado e relacionamentos continuados embutidos em uma estrutura familiar continuada, ao mesmo tempo em que ignora efetivamente o indivíduo contextualizado. Em nome da contextualização, este discurso cria uma subjetividade ilusória que pode então ser controlada pelo discurso da necessidade.

\subsection{A discursividade do conhecimento social}

O tema final que se pode detectar no trabalho de vários acadêmicos que estão produzindo a nova literatura em disputas civis, litigância e processo não lida com o direito, mas com o próprio conhecimento social. Representa um repensar a natureza e o objetivo da pesquisa empírica. Esse repensar não é limitado às disputas e à área da litigância, eis que afeta o todo toda da pesquisa em ciências sociais no e sobre o direito. Muitos dos acadêmicos que tem escrito extensivamente sobre litigância, relações entre cliente e advogado, ADR, e outros temas delineados acima ${ }^{108}$ tem ao mesmo tempo se engajado em uma crítica epistemológica mais ampla. Como resultado, seu trabalho na sociologia do processo civil manifesta uma atitude diferente em direção ao processo de pesquisa do que aquele refletido na maioria dos trabalhos da Law and Society pós-realista.

O temo "discursividade do conhecimento social" re-

106 Id. nas páginas 731-35, 740-44.

107 Id. na página 761.

108 Notório entre esses estão Kristin Bumiller, Austin Sarat e Susan Silbey. Para uma discussão das visões de Bumiller sobre o conhecimento social, ver supra nota 71 . Sarat e Silbey tem escrito extensivamente sobre essas questões. Ver supra nota 24 e fontes lá citadas. fere-se à ideia de que as áreas de conhecimento tais como o conhecimento legal e a sociologia do direito são discursos que contribuem para a construção da sociedade, e não espelhos neutros que simplesmente refletem uma realidade social objetiva. Nos anos recentes, acadêmicos de várias áreas perceberam que representações da sociedade afetam o modo pelo qual a sociedade é entendida e organizada. ${ }^{109}$ Esse reconhecimento os levou a aceitar a proposição de que acadêmicos têm a responsabilidade de investigar os valores que seu trabalho adota e os projetos sociais que ele apoia. Na tradição da Law and Society, esse reconhecimento tem levado alguns a questionar se a sociologia do direito tem sido suficientemente atenta aos efeitos produzidos na sociedade por suas escolhas de questões, seus métodos de investigação e suas técnicas de interpretação. ${ }^{110}$ Ademais, o reconhecimento da discursividade levou os acadêmicos da Law and Society a procurarem mais distanciamento de dogmas oficiais, objetivos de política pública e as assim apresentadas agendas de reforma. ${ }^{111}$

O impacto dessa nova consciência pode ser visto na literatura acima resenhada e nos temas que ela tem gerado. Duas características salientes desse trabalho se destacam. Primeiro, há uma disposição em se questionar a visão social mais ampla embutida no pensamento atual sobre o direito e consagrada nas instituições processuais atuais. Como foi mostrado, a nova literatura não toma como certo as histórias que o pensamento mainstream conta sobre a natureza do indivíduo, da sociedade e do direito. Em vez disso, os autores da nova literatura reconhecem que essas histórias se apoiam em visões sociais contestáveis. Eles estão preparados para trazer à luz esses pressupostos contestáveis para apreciação crítica. $\mathrm{E}$ eles tem mostrado uma disposição, às vezes, para firmar visões alternativas como a noção comunitária do indivíduo contextualizado.

109 Exemplos disso podem ser encontrados na produção sobre o feminismo. Ver, de modo amplo, Lauretis (ed.), 1986; C. Weedon, 1987. Para exemplos em outras áreas, ver A. Giddens, 1984 (sociologia); Collier \& Yanagisako, 1987 (antropologia).

110 Para uma revisão de recentes trabalhos da Law and Society que começaram a reconhecer que o conhecimento social constitui a sociedade - isto é, discursivo - e as implicações desse reconhecimento em questões, métodos e técnicas interpretativas, ver Trubek \& Esser, 1989, supra nota 14. Ver também Trubek, 1984, supra nota 63.

111 Ver, e.g, Silbey \& Sarat, 1988, supra nota 24. 
Segundo, esses autores estão dispostos a articular as vozes de pessoas e grupos que são afetados pelo direito, mas cujas perspectivas são negligenciadas ou subestimadas pelo pensamento predominante. Esses autores são autoconscientes sobre seus papeis em um processo de construção de áreas do conhecimento que terão um impacto na vida social e eles estão preocupados que este processo reflita os pontos de vista diferentes daqueles das elites acadêmicas. Essa preocupação é visível no modo como Sarat e Felstiner nos mostram a perspectiva de clientes cujas expectativas pelo direito são frustradas pelo comportamento manipulativo de advogados. ${ }^{112}$ Também é clara na decisão autoconsciente de Bumiller de dar voz a mulheres negras e outras vítimas ludibriadas em um sistema processual ostensivamente desenhado para protegê-las. ${ }^{113}$ Essa proteção vem de forma mais contundente nos esforços inflamados de Fineman de demonstrar como os interesses de mães divorciadas e suas crianças têm sido negligenciados por aqueles que procuram transformar o processo de divórcio por meio da instrução de discursos de necessidade. ${ }^{114}$

\section{Conclusão}

A combinação de temas que emergem na sociologia do processo civil demonstra como o desenvolvimento de uma prática crítica está levando a produção da Law and Society além dos limites estabelecidos no período pós-realista. Os acadêmicos cujos trabalhos foram aqui sintetizados são um pequeno grupo e seus trabalhos são uma pequena porção de toda a pesquisa empírica que está sendo produzida atualmente sobre disputas, litigância e processo. Mas porque eles delimitaram um novo e mais crítico papel para a pesquisa empírica, seus esforços iniciais representam uma importante e nova fase da tradição empírica inicialmente lançada pelos realistas como um instrumento acessório para reformas processuais. Começada como uma criada altamente técnica para o trabalho de reformadores mainstream, a sociologia do processo civil está se encaminhando para uma completa prática crítica na qual acadêmicos da Law and Society tendem tanto a questionar os obje- tivos do sistema jurídico, quanto a adotá-los. Esse movimento, se totalmente levado a cabo, pode ser a verdadeira vingança da criada.

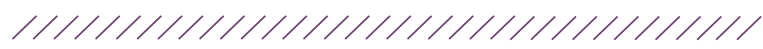




\section{Referências}

Blumberg, A. S. (1967). The Practice of Law as Confidence Game: Organizational Cooptation of a Profession. Law \& Society Review, 1(2), 15-39.

Brazil, W. D. (1978). The adversary Character of Civil Discovery: A Critique of Proposals for Change. Vanderbilt Law Review, 6(31), 1295-1361.

Bumiller, K. (1987). Victims in the Shadow of the Law: A Critique of the Model of Legal Protection. Signs: Journal of Women in Culture and Society, 12(3), 421-439.

Bumiller, K. (1988). The Civil Rights Society: The Social Construction of Victims. Baltimore, Md.: The Johns Hopkins University Press.

Bush, R. A. B. (1989). Defining Quality in Dispute Resolution: Taxonomies and Anti-Taxonomies of Quality Arguments. Denver University Law Review, 3(66), 335-376.

Cappelletti, M., \& Garth, B. G. (1978). Access to Justice: The Newest Wave in the Worldwide Movement to Make Rights Effective. Buffalo Law Review, 2(27), 181-292.

Cappelletti, M., \& Garth, B. G. (1981). Access to justice and the welfare state: an introduction.

Cohen, F. S. (1935). Transcendental Nonsense and the Functional Approach. Columbia Law Review, 6(35), 809-849.

Collier, J. F., \& Yanagisako, S. J. (1987). Toward a Unified Analysis of Gender and Kinship. In Collier, J. F., \& Yanagisako, S. J. (Ed.) Gender and kinship: essays toward a unified analysis. Stanford, CA: Stanford University Press.

Coombe, R. J. (1989). Room for Manoeuver: Toward a Theory of Practice in Critical Legal Studies. Law \& Social Inquiry, 14(1), 69.

Dreyfus, H. L., \& Rabinow, P. (1983). Michel Foucault: Beyond Structuralism and Hermeneutics. Harvester Press.

Felstiner, W. L., Abel, R. L., \& Sarat, A. (1980-81). The Emergence and Transformation of Disputes: Naming, Blaming, Claiming... Law \& Society Review, 15(3/4), 631.

Fineman, M. (1988). Dominant Discourse, Professional Language, and Legal Change in Child Custody Decisionmaking. Harvard Law Review, 101(4), 727.

Fischl, R. M. (1986). Some Realism About Critical Legal Studies. University of Miami Law Review, 41(505), 526-28.
Foucault, M. (1977). Discipline and Punish.

Foucault, M. (1978). The history of sexuality. The use of pleasure. London: Allen Lane.

Foucault, M. (1980). Power/knowledge. a selected interviews and other writings 1972-77. New York: Pantheon Books.

Gabel, P. (1984). The Phenomenology of Rights-Consciousness and the Pact of the Withdrawn Selves. Texas Law Review, 62, 1563.

Galanter, M. (1974). Why the "Haves" Come out Ahead: Speculations on the Limits of Legal Change. Law \& Society Review, 9(1), 95-160.

Galanter, M. (1981). Justice in Many Rooms: Courts, Private Ordering, and Indigenous Law. The Journal of Legal Pluralism and Unofficial Law, 13(19), 1-47.

Giddens, A. (1984). The Constitution of Society: Outline of the Theory of Structuration. Berkeley and Los Angeles: University of California Press.

Gordon, R. (1982). New developments in Legal Theory. In D. Kairys (ed.), The Politics of Law: A Progressive Critique, (pp. 287-89). New York: Pantheon Books.

Hunt, A. (1985). The Ideology of Law: Advances and Problems in Recent Applications of the Concept of Ideology to the Analysis of Law. Law \& Society Review, 19(1), 11-37

Kennedy, D. (1976). Form and Substance in Private Law Adjudication. Harvard Law Review, 89, 16851778.

Kennedy, D. (1980). Toward an Understanding of Legal Consciousness: The Case of Classical Legal Thought in America, 1850-1940. Research in Law and Sociology, 3, 3-24.

Lauretis, T. D. (1986). Feminist studies/critical studies. Houndmills: Macmillan Pr.

Llewellyn, Karl N. (1931). Some Realism About Realism - Responding to Dean Pound. Harvard Law Review, 44(8), 1222-1264.

Locke, J. (1967). Two Tracts of Government. P. Abrams (ed.). Cambridge: Cambridge University Press.

Macaulay, S. (1979). Lawyers and Consumer Protection Laws. Law \& Society Review, 14(1), 115-171.

Mather, L., \& Yngvesson, B. (1980). Language, Audience, and the Transformation of Disputes. Law \& Society Review, 15(3/4), 775-821.

Merry, S. E. (1985). Concepts of Law and Justice Among Working-Class Americans: Ideology as 
Culture. Legal Studies Forum 9(1), 59.

Miller, R. \& Sarat, A. (1980-81). Grievances, Claims, and Disputes: Assessing the Adversary Culture. Law \& Society Review, 15(3/4), 525.

Milne, A. \& Folberg, J. (1988). The Theory and Practice of Divorce Mediation: An Overview. In Divorce Mediation: Theory and Practice (J. Folberg \& A. Milne eds). New York: The Guilford Press.

Minority Critique of the Critical Legal Studies Movement. (1987). Harvard Civil Rights-Civil Liberties Law Review 22(2), 297.

Nader, L. (1969). Styles of Court Procedure: To Make The Balance. In L. Nader ed. Law in Culture \& Society.

Note, Plausible Pleadings: Developing Standards for Rule 11 Sanctions. Harvard Law Review, 100, 630, 645-47 (1987).

Peller, G. (1985). The Metaphysics of American Law. California Law Review, 73(4), 1151-1290.

Rosenthal, D. E. (1977). Lawyer and client: Who's in charge (2nd ed.). New Brunswick, NJ: Transaction Books.

Sandel, M. (1962) Liberalism and the Limits of Justice. Cambridge: Cambridge University Press.

Sarat, A. Legal (1985). Effectiveness and Social Studies of Law: On the Unfortunate Persistence of a Research Tradition. Legal Studies Forum, 9(1), 23.

Sarat, A., \& William L. F. Felstiner. (1986). Law and Strategy in the Divorce Lawyer's Office. Law \& Society Review, 20(1), 93-134.

Schiegel, J. H. (1979). American Legal Realism and Empirical Social Science: From the Yale Experience. Buffalo Law Review, 28(459), 459-569.

Silvey, S. S., \& Sarat, A. (1987). Critical Traditions in Law and Society Research. Law \& Society Review, 21(1) 165-174.

Silvey, S. S., \& Sarat, A. (1988). The Pull of the Policy Audience. Law \& Policy, 10(2-3), 97-166.

Silvey, S. S., \& Sarat, A. (1989). Dispute Processing in Law and Legal Scholarship: From Institutional Critique to the Reconstruction of the Juridical Subject. Denver University Law Review, 66(3), 437-498.

Singer, J. (1988). Legal Realism Now. California Law Review, 76(2), 465-544.

Singer, J. W. (1982). The Legal Rights Debate in Analytical Jurisprudence from Bentham to Hohfeld. Wisconsin Law Review, 975-1059.

Special Issue on Dispute Processing and Civil Litiga- tion. Law \& Society Review, 391 (1980-81).

Trubek, D. (1984). Where the Action Is: Critical Legal Studies and Empiricism. Stanford Law Review, 36(1/2), 575-622.

Trubek, D. (1986). Max Weber's Tragic Modernism and the Study of Law in Society. Law \& Society Review, 20(4), 573-598.

Trubek, D. (1989). Programmatic Thought and the Critique of the Social Disciplines. In M. Perry (ed.), Critique and Construction. Cambridge: Cambridge University Press.

Trubek, D., \& Esser, J. (1989). "Critical Empiricism" in American Legal Studies: Paradox, Program, or Pandora's Box? Law \& Social Inquiry, 14(1), 3-52.

Tushnet, M. (1984). An Essay on Rights. Texas Law Review, 62, 1364.

Unger, R. M. (1975). Knowledge and Politics. New York: The Free Press.

Unger, R. M. (1976). Law in Modern Society. New York: The Free Press.

Unger, R. M. (1984). Passion: An Essay on Personality. New York: Free Press.

Unger, R. M. (1986). The Critical Legal Studies Movement. London, New York: Verso.

Unger, R. M. (1987a). Plasticity into Power. Cambridge: Cambridge University Press.

Unger, R. M. (1987b). Politics: A Work in Constructive Social Theory. Cambridge: Cambridge University Press.

Unger, R. M. (1987c). Social Theory: Its Situation and Its Task. Cambridge: Cambridge University Press.

Villmoare, A. H. (1985). The Left's Problems with Rights. Legal Studies Forum, 9(1), 39-46.

Wahrhaftig, P. (1982). An Overview of Community-Oriented Citizen Dispute Resolution Programs in the United States. The Politics of Informal Justice, 1, 75-97.

Weber, M. (1980). Economy and Society. (G. Roth \& C. Wittich eds.). Berkeley: University of California Press.

Weedon, C. (1987). Feminist practice and poststructuralist theory. Malden MA: Blackwell Pub.

Yngvesson, B. (1985). Re-examining Continuing Relations and the Law. Wisconsin Law Review, 623-46. 